\title{
Health Must Be Recognized as the Human Right It Is: Héctor Javier Sánchez MD MS \\ Senior Researcher, Department of Society, Culture and Health El Colegio de la Frontera Sur (ECOSUR), Chiapas, Mexico
}

\section{Alina Alerm-González MD MS}

Dr Héctor Javier Sánchez specializes in public health and research methodology and holds a master's degree in epidemiology. He is a senior researcher in the Society, Culture and Health Department at El Colegio de la Frontera Sur, Mexico. The Colegio is a public research institution concentrating on environmental, economic and social issues related to a sustainable future for Mexico's southern border area, and belongs to the National Council of Science and Technology (CONACYT). In Chiapas State, the country's poorest region and home to many indigenous peoples, Dr Sánchez has carried out studies on $\mathrm{TB}$, poverty and health, domestic violence, human rights, maternal-child health and the effect of agrochemicals on human health.

He has been a member of the National System of Researchers since 2000, belongs to the Health Research Group for Africa and Latin America (GRAAL), and is technical secretary of the Latin American Forum of Health Research Ethics Committee (FLACEIS). MEDICC Review interviewed Dr Sánchez by e-mail on COVID-19 and its impact on Chiapas, indigenous populations and Mexico's health system.

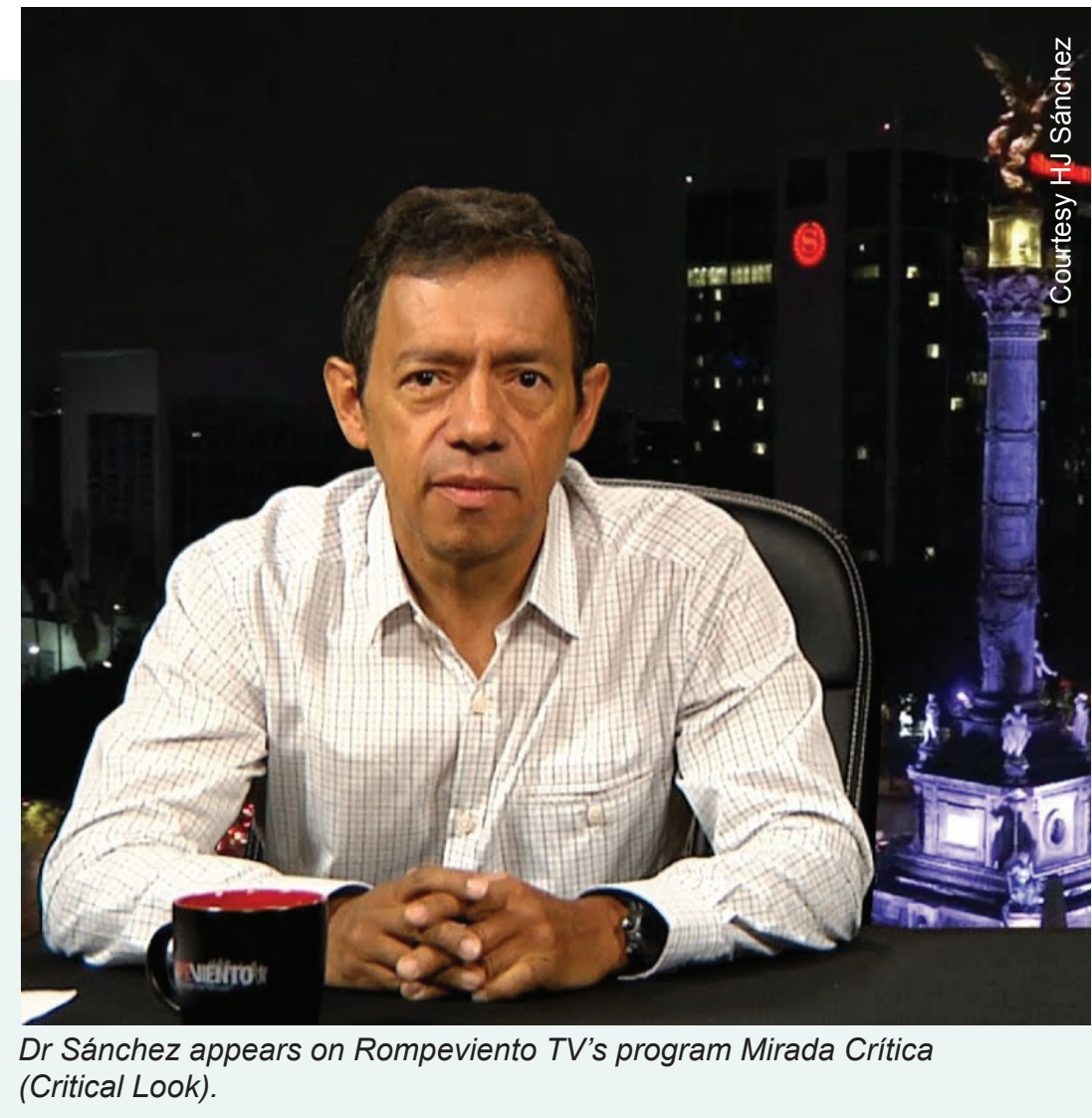

\begin{abstract}
MEDICC Review: What structural and health challenges do indigenous populations face-in Chiapas where you work and elsewhere-during the current pandemic?
\end{abstract}

Héctor Javier Sánchez: Several fundamental aspects need to be considered when analyzing the health and economies of indigenous populations. First, indigenous peoples often live in conditions of extreme poverty. Second, native populations, who are among the poorest and most marginalized sectors of society, have notable difficulties in accessing and navigating the public health system. And third, Chiapas, sharing more than 600 kilometers of unpatrolled border with Guatemala, is a transit site for migrants traveling to the United States. Recently, thousands of migrants fleeing their countries have been held in detention facilities in this region-facilities that open the door to infectious disease transmission.

It is highly probable that the COVID-19 pandemic will have adverse consequences not only on the health sector, but contribute to higher levels of poverty among indigenous populations as well. This is, of course, due to the structural violence under which these populations have suffered for generations.
MEDICC Review: Specialists predict a serious economic recession as a consequence of COVID-19. What would a recession mean for these indigenous populations in Chiapas? What social and economic conditions do they face?

Héctor Javier Sánchez: Before the emergence of COVID-19, the UN Economic Commission for Latin America and the Caribbean (ECLAC) estimated that Latin American and Caribbean (LAC) economies would be facing a period of minimal growth, predicting just $0.1 \%$ in 2019 and $1.3 \%$ in 2020 . Indeed, the entire LAC region, including Mexico, has shown six consecutive years of slowed growth.[1] Along with this general economic decline, there was sustained deterioration in the quality of employment-regionally, the largest source of new jobs is in the informal sector, characterized by low and unstable income, precarious social conditions and weak worker protections.[2] Given these circumstances, policies need adopting that stimulate growth and reduce inequality.

Chiapas is the Mexican state with the highest levels of poverty, $76.2 \%$.[3] While $10.1 \%$ of the Mexican population are indigenous,[4] in Chiapas, at least $27 \%$ of the more than 5 million people are indigenous and speak indigenous languages 
(Tseltal, Tsotsil, Chol, Zoque, Tojolabal and Lacandón, among others); $14 \%$ of them are monolingual, and do not speak Spanish. [5] Economic, educational, and health conditions are worse in indigenous populations than in non-indigenous populations: illiteracy rates are higher $(17.8 \%$ vs. $5.5 \%)$, average years of education are lower (3.7 years vs. 9.4 years), rates of extreme poverty are higher (31.8\% vs. $7.1 \%)$, lack of social security is higher $(79.4 \%$ vs. $56 \%)$, and so is lack of income sufficient to ensure basic nutrition (44\% vs. $18 \%)$.[4]

\section{MEDICC Review: Can you talk a little about health care for indigenous peoples in Mexico?}

Héctor Javier Sánchez: According to the National Human Rights Commission (CNDH), indigenous peoples in Mexico suffer from denial of services; inadequate provision of public health services, including medical negligence, discrimination, forced contraception, shortage of medications, confidentiality violations, irregular record keeping and failure to provide information on the patient's state of health; as well as insufficient infrastructure to provide health care.[6] What's more, the conditions under which these services are provided are even more precarious. $\mathrm{PAHO} /$ WHO recommends a minimum investment in health equivalent to $6 \%$ of GDP. In 2018, Mexico barely allocated $2.81 \%$.[7]

Additionally, in Mexico, out-of-pocket expenses as a percentage of total healthcare spending is very high, above $40 \%$. In other countries in the region, such as Cuba and Uruguay, this is only $10.3 \%$ and $17.4 \%$, respectively.[8] This is an important indicator because the vast majority of indigenous populations have high indirect healthcare costs (transport, lodging, food, medicines) when they receive care in urban centers due to the scarcity of services in their communities.

MEDICC Review: Clearly, these factors do not bode well for the health of indigenous communities beyond the pandemic...

\section{...other health problems of indigenous people in Mexico could be exacerbated during the critical stage of the pandemic}

\begin{abstract}
Héctor Javier Sánchez: If more health resources are not made available, other health problems could be exacerbated during the critical stage of the pandemic and beyond, including:
\end{abstract}

1. A rise in infectious disease rates such as tuberculosis, HIV/ AIDS, other respiratory infections, and vaccine-preventable diseases (like whooping cough in children). This increase would not be adequately addressed if there is a shortage of health resources, including well-equipped health units, trained personnel and supplies of necessary medications and vaccines.

2. Increased maternal mortality. Chiapas has the highest maternal mortality of any state in our country. According to figures from the Maternal Mortality Observatory in Mexico, more than half of maternal-mortality deaths occur among indigenous women, despite the fact that they represent less than $28 \%$ of the female population.[9]

3. Increase in nutritional disorders-both those due to deficiency (mainly chronic infant malnutrition) as well as overweight/ obesity. In turn, all three of these conditions are strongly linked to diabetes mellitus.
4. Increase in mental and social disorders including fear, posttraumatic stress, suicidal ideation (and suicides) and social violence. These conditions can be exacerbated by the recession (or depression) expected to follow the pandemic, and can lead to higher levels of poverty, insecurity and social unrest.

In addition to these concerns, aspects that deserve special attention in indigenous areas include violence against women, ranging from physical and psychological abuse to femicide; living conditions of migrants who return to their communities; health status of the incarcerated; and accountability for use of health resources.

MEDICC Review: This is a dire state of affairs. Do you foresee any positive outcomes from the pandemic for the health of indigenous people?

Héctor Javier Sánchez: Once the pandemic is controlled, and taking into account the conditions of poverty, marginalization, exclusion and lack of basic health services addressing their needs in culturally- and linguistically-appropriate ways, indigenous communities could see positive economic and health effects postCOVID-19. These include:

1. Some mechanical ventilators acquired during the pandemic will remain available locally.

2. Perhaps, although less likely, the pandemic could bring greater awareness of and sensitivity to the unmet health needs of indigenous communities, and the government and health system may respond accordingly. Consider that the lack of personal protective equipment (PPE) for health personnel during the pandemic has been so great that doctors in indigenous communities have had to make 'protective' suits out of plastic garbage bags.[10]

3. We may see greater recognition of the importance of community health workers, particularly midwives-not just in care during pregnancy and low-risk deliveries, but as true community health workers at the primary care level. Unfortunately, government policies in Mexico in recent years have devalued and excluded midwives from their work in indigenous communities.

MEDICC Review: Given these circumstances, how does Mexico move forward towards universal health care that meets the needs of indigenous populations of Chiapas and elsewhere?

Héctor Javier Sánchez: First, health must be recognized as the human right that it is. The capitalist vision of health as merchandise has to be discarded-the paradigm where the doctor-patient relationship is a provider-client relationship. In these circumstances, collective health is viewed disparagingly, and importance is afforded only to clinical specialties. Doctors choosing to be epidemiologists, primary healthcare professionals or public health specialists are viewed pejoratively, as practicing 'inferior' specialties. This view must change drastically to acknowledge the full value of specialties like family medicine, public health, community health and epidemiology.

Who would be opposed to health care for all, universal health? I think the great majority of people would favor it, but not broken down into 'basic packages', but rather truly comprehensive health care, considering and meeting the needs of different populations. Three major aspects stand out in this regard: 
1. Financing must ensure sufficient budget for the organization, operation, supervision and accountability of health services, and must be provided through either general or sales taxes.

2. A larger number of interventions related to a broader range of diseases must be covered universally. The previous government tried to implement universality of health services, but only for a limited number of listed conditions and interventions under the so-called 'Popular Insurance' program (created in 2003; dissolved in 2020 and replaced by the Institute for Health and Well-being, INSABI). Popular Insurance operated as public health insurance for that portion of the population not participating in social security. People had to take out 'complementary' private insurance for conditions not covered under this program, such as chronic kidney disease. In fact, as a result, the burden of most illnesses was shifted from government to the population itself, and care depended on each person's ability to pay for private services. The private sector, needless to say, supported this scheme.

3. Thus, as a population we must still mobilize to demand true universal health with comprehensive, not partial, coverage. And we must also continue to fight to improve the social determinants of health. COVID-19 raises the question: how do we proceed after the pandemic? If the population doesn't assume a collaborative stance based on solidarity and collectivity, we will be stuck with the vision imposed until now. Let's not forget that immobilizing social movements could be collateral damage from measures taken to stem the epidemic, such as physical and social distancing. So coordination between and within communities, in addition to mobilizing social movements, will be very important in defining changes shaping the health sector and in fulfilling the unmet needs of indigenous peoples, whether in Chiapas or elsewhere in Mexico.

\section{MEDICC Review: Are there examples of this type of collabo- ration during the pandemic?}

Héctor Javier Sánchez: In Los Altos de Chiapas, an indigenous region where there is greater community coordination and the Zapatista National Liberation Army still has influence, various communities quarantined returning migrants and suspended public transportation to some areas to prevent possible transmission. This region lacks information in indigenous languages, has insufficient health services and few protocols based on an intercultural approach providing for the protection and medical care of the population.

Concerning social mobilization, the creation of social observatories like those dedicated to maternal death, HIV and tuberculosis may serve as pressure mechanisms to protect the health sector against government 'adjustment measures' or budget cuts. They can also provide guidance regarding resource allocation to ensure basic health services and those related to new COVID-19 outbreaks (or other epidemics). Additionally, they can provide disease surveillance and serve as a source of accountability to society.

\section{Government responsibility \\ cannot be reduced to \\ minimum health service \\ packages, especially for the \\ most vulnerable populations \\ such as indigenous peoples}

Structurally, constitutional reforms and corresponding laws must be promoted and implemented that guarantee the right to health. Government responsibility cannot be reduced to minimum health service packages,[11] especially for the most vulnerable populations, such as indigenous peoples.

\section{MEDICC Review: How might the pandemic affect health inequalities in the future, especially for vulnerable popula- tions?}

Héctor Javier Sánchez: COVID-19 has displaced all other diseases from the spotlight and revealed governments' poor preparation to face a new infectious agent. Moreover, the pandemic laid bare the social, health, psychological, political and economic problems plaguing the planet. At the health level, it exposed the frail hospital and laboratory infrastructure, and shortage of equipment and properly prepared and protected human resources. It also exposed the lack of intersectoral policies needed to face such a pandemic.

In Chiapas, as in other regions, COVID-19 is monopolizing resources of all kinds, leaving other health problems without due coverage, neglected. When the COVID-19 curve flattens, it will leave a clearer picture of the state of these neglected diseases, like tuberculosis. Even before the pandemic, TB was underdiagnosed, had high dropout rates for treatment in areas of socioeconomic marginalization, and widely documented multidrug-resistant cases, resulting in high levels of mortality. This is particularly true for disadvantaged areas like Chiapas and other regions with large indigenous populations, characterized by low human development indices.[12-14]

Likewise, there are various diseases that especially affect indigenous and rural areas, and which have been poorly attended by health services. These include dengue, Chagas disease, Zika and chikungunya; although the extent of chikungunya's prevalence in the area remains uncertain.

This situation illustrates the challenges faced by Chiapas and other regions with the twin conditions of high socioeconomic marginalization and social exclusion. In summary, COVID-19 will have a much greater negative impact if actions are not taken that reinforce universal access to, and the quality of, health services and address the social determinants of health. -1 -

\section{REFERENCES}

1. Economic Commission for Latin America and the Caribbean (CEPAL) [Internet]. Santiago de Chile: Economic Commission for Latin America and the Caribbean (CEPAL); c2020. Comunicado de prensa. El período 2014-2020 sería el de menor crecimiento para las economías de América Latina y el Caribe en las últimas siete décadas: CEPAL; 2019 Dec 12 [cited 2020 Apr 3]; [about 3 p.].
Available at: https://www.cepal.org/es/comunica dos/periodo-2014-2020-seria-menor-crecimiento -economias-america-latina-caribe-ultimas-siete. Spanish.

2. Economic Commission for Latin America and the Caribbean (CEPAL). Estudio Económico de América Latina y el Caribe. El nuevo contexto financiero mundial: efectos y mecanismos de transmisión en la región. 2019 (LCPUB.2019/12P). Santiago de Chile: Economic Commission for Latin America and the Caribbean (CEPAL); 2019. Spanish.

3. Forbes Mexico [Internet]. Mexico City: Forbes; c2020. Economía y Finanzas. Los 10 estados con más pobres en México; 2017 Dec 30 [cited 2020 Apr 3]; [about 3 p.]. Available at: https:// 
www.forbes.com.mx/los-10-estados-con-mas -pobres-en-mexico/. Spanish.

4. Instituto Belisario Domínguez del Senado de la República. Al día: las cifras hablan Número 71. Día internacional de los Pueblos Indígenas [Internet]. Instituto Belisario Domínguez del Senado de la República (MX): Mexico City; [cited 2020 Apr 3]. 13 p. Available at: http://bibliodigitalibd.se nado.gob.mx/bitstream/handle/123456789/3652/ AD-71.pdf?sequence=1\&isAllowed=y. Spanish.

5. Cuéntame de México [Internet] Mexico City: National Institute of Statistics and Geography (INEGI); c2020. Los idiomas hablados en Chiapas; [cited 2020 Apr 3]. Available at: http://www.cuentame.inegi.org. $\mathrm{mx} /$ monogra fias/informacion/chis/poblacion/diversidad .aspx?tema=me\&e=07. Spanish.

6. National Human Rights Commission (MX). El derecho a la salud de los pueblos indígenas. Servicios y atención en las clínicas de las comunidades [Internet]. Mexico City: National Human Rights Commission (MX); 2018 Jul [cited 2020
Apr 3]. 22 p. Available at: https://www.cndh.org .mx/sites/all/doc/cartillas/2015-2016/04-Salud -Pueblos-Indigenas.pdf. Spanish.

7. México - Gasto público salud [Internet]. Madrid: Expansión / Datosmacro.com; [cited 2020 Apr 3]; [about 2 p.]. Available at: https://datosmacro.expan sion.com/estado/gasto/salud/mexico. Spanish

8. Pan American Health Organization; World Health Organization. Indicadores básicos 2019. Tendencias de la salud en las Américas [Internet]. Washington, D.C.: Pan American Health Organization; 2019 Oct 1 [updated 2019 Oct 31; cited 2020 Apr 3]. 21 p. Available at: https://iris.paho .org/handle/10665.2/51543. Spanish.

9. Vega M. Salud en Chiapas: la maternidad, solo un privilegio. Mexico City: Grupo de Información en Reproducción Elegida; c2017 [cited 2020 Apr 3]; [about 6 p.]. Available at: https://www.animal politico.com/salud-en-chiapas/maternidad/index .html\#/. Spanish.

10. Mariscal A. Chiapas: usan bolsas de plástico para "evitar" contagios de Covid-19. Aristegui Noticias
[Internet]. 2020 Apr 3 [cited 2020 Apr 3]. Available at: https://m.aristeguinoticias.com/0304/mexico/ chiapas-usan-bolsas-de-plastico-para-evitar -contagios-de-covid-19/. Spanish.

11. León-Cortés JL, Leal Fernández G, SánchezPérez HJ. Health reform in Mexico: governance and potential outcomes. Int J Equity Health. 2019 Feb 7;18(1):30.

12. Pérez-Molina A, Sánchez-Pérez HJ, Yanes-Pérez M, Arana Cedeño M. Tuberculosis care in Mexico's Chiapas Highlands region: a right to health analysis. Health Human Rights J. 2020 Jan 27;21(2).

13. Nájera-Ortiz, Sánchez-Pérez HJ, Ochoa DíazLopez $\mathrm{H}$, et al. The poor survival among pulmonary tuberculosis patients in Chiapas, Mexico: the case of Los Altos region. Tuberc Res Treatment. 2012; Article ID 708423.

14. Sánchez-Pérez HJ, Díaz-Vázquez A, NájeraOrtíz JC, Balandrano S, Martín-Mateo M, et al. Multidrug-resistant pulmonary tuberculosis in Los Altos, Selva and Norte regions of Chiapas, Mexico. Int J Tuber Lung Dis. 2010;14(1):34-9.

Published July 31, 2020 https:doi.org/10.37757/MR2020.V22.N3.6 